\title{
NARROW BAND IMAGING VERSUS CHROMOENDOSCOPY AND CONVENTIONAL COLONOSCOPY IN DETECTION OF DIFFERENT COLONIC LESIONS
}

\author{
By
Galal Abu-Farrag ${ }^{1}$ Mohamed Bastawy ${ }^{1}$, Ali Ibrahim ${ }^{1}$, Nasser El-Fikky ${ }^{2}$ and Ahmed Hashish ${ }^{1}$ \\ ${ }^{1}$ Hepatology, Gastroenterology and Infectious diseases department, Al-Azhar Faculty of \\ Medicine \\ ${ }^{2}$ Pathology Department, Al-Azhar Faculty of Medicine \\ Corresponding author: Galal Abd El-Hameed Abu-Farrag,
}

Mobile: 01204416987, E-mail: drgalal2009@yahoo.com

\begin{abstract}
Background: Narrow band imaging (NBI) is a new technique that uses optical filters for imaging of mucosal morphology. Thus, it can identify colonic polyp/mass through pit pattern and vascular pattern.

Objective: To evaluate the efficacy of NBI in comparison with chromo endoscopy and conventional colonoscopy for detection of colorectal lesions.

Patients and Methods: This study was carried out at Hepatology, Gastroenterology and Infectious diseases Department, Al-Hussein University Hospital. The study population included 200 patients from April 2019 to November 2020.By colonoscopy, 37 patients were excluded that had internal hemorrhoids, colonic diverticula, colonic ulcers or no abnormal colonoscopy finding. The rest 163 patients had colonic polyp/masses were divided into two groups. Group I included 102 patients who had colonic polyps, and Group II included 61 patients with colonic masses. The two groups underwent NBI (using NICE classification), chromo endoscopy (using Kudo classification), and biopsies were taken for histopathology.

Results: There was a statistically significant relation between histopathological characters of the polyps/masses and their characters by NBI /chromo endoscopy $(\mathrm{P}<0.001)$. NBI /chromo endoscopy can detect adenocarcinoma with $100 \%$ sensitivity and $94.7 \%$ specificity. Sensitivity and specificity for hyperplastic polyp was $93.5 \%$ and $91.5 \%$ respectively. Adenoma was $90.9 \%$ and $89.4 \%$ respectively. Sensitivity and specificity for malignant masses was $100 \%$ and $60 \%$ respectively.

Conclusion: NBI can detect either colorectal polyp or mass, and predict its histology more rapid and simple than chromo endoscopy which needed stains and time consuming. Thus, can reduce the cost of the health system and the risk of polypectomy.
\end{abstract}

Keywords: Colonic polyp/ mass, narrow band imaging, Chromo endoscopy.

\section{INTRODUCTION}

Narrow-band imaging (NBI) is one of the methods of optical chromo endoscopy that uses high resolution colonoscopy to give a detailed description of the surface tissue of the neoplasm and its vascular pattern, and thus characterizes the polyps while performing endoscopy so-called virtual biopsy, which would be equal to 
the histological feature (Patrun et al., 2018).

NBI system is based on the properties of the hemoglobin as the major tissue chromophore. The peak absorption of oxyhemoglobin is at $415 \mathrm{~nm}$ (blue light). A secondary peak of absorption is at 540 $\mathrm{nm}$ (green light). NBI technique uses a special filter placed in the light source that allows only narrow band of blue and green light to pass through (Vişovan et al., 2017).

$\begin{array}{cl}\text { The NBI International Colorectal } \\ \text { Endoscopic } & \text { (NICE) Classification }\end{array}$ applicable for non-magnified NBI imaging, have been validated by a group of international experts in order to characterize colonic polyps and uses mucosal color, vessel and surface pattern to differentiate between hyperplastic polyps ,adenoma and invasive carcinomas (Utsumi et al., 2015).

Chromo endoscopy involves topical application of stains such as indigo carmine where on application they seep between grooves and crevices providing overall details of the contour of the mucosal surface. Thus, aids the endoscopist in highlighting and characterizing lesions in the GIT during endoscopy through pit pattern (Kudo classification) (Kheir et al., 2016). Type I round pit reveal normal mucosa. Type II stellar or asteroid pit reveal hyperplastic, sessile serrated adenoma/ polyp. Type IIIS small rounded or tubular pits reveal adenoma with low grade dysplasia. Type IIIL large rounded or tubular pits reveal adenoma with low grade dysplasia. Type IV branch like or gyrus like pits reveal adenoma with high grade dysplasia. Type
$\mathrm{V}$ non-structured or irregular pits reveals malignant (Carlo et al., 2014).

This study aimed to evaluate the efficacy of narrow band imaging in comparison with chromo endoscopy and conventional colonoscopy for detection of colorectal lesions.

\section{PATIENTS AND METHODS}

This study had been accomplished at Al-Azhar University Hospitals, Hepatology, Gastroenterology and Infectious diseases Departments in Cairo, at the period from April 2019 till November 2020. The study protocol adopted was approved by the Medical Ethics Committee; Al-Azhar Faculty of Medicine .All patients gave written informed consents. Study enrolled 200 patients which had the following inclusion criteria (rectal bleeding, chronic abdominal pain or discomfort, chronic constipation, family history of colorectal carcinoma, patients who had past history of colorectal tumor resection, past history of polypectomy or fecal occult blood in stool is positive). Exclusion criteria included pregnancy, patients who had intestinal obstruction or IBD.

Patients subjected to the following: History of (Abdominal pain, change in bowel habits, rectal bleeding, weight loss, chronic constipation, family history of CRC and past history of polypectomy), General, local examinations and laboratory investigations (CBC, ESR, CRP, CEA and occult blood in stool), Colonoscopy procedure: Well preparation of bowel was done then examined by:

I. White light colonoscopy revealed 163 patients had colonic polyps /masses then categorized into two groups: 
Group 1: Patients with colonic polyps and Group 2: Patients with colorectal masses.

II. NBI colonoscopy: The Olympus 290 series endoscopy system (EVIS LUCERA ELITE), NICE classification was used.

III. Chromo endoscopy: Indigo carmine stain $(0.4 \%)$ was sprayed directly onto the mucosa. Kudo classification was used and histopathological examination for the biopsies taken.

Statistical analysis: Data were expressed using SPSS software package version 20.0 and described using mean \pm standard deviation. The Chi square test was used to assess statistical significance of mean difference between the studied groups. The probability level of $\mathrm{P}<0.05$ was set for statistical significance.

\section{RESULTS}

By colonoscopy, out of 200 patients had included in this study; 102 patients had colonic polyps, 61 patients had colonic masses and the rest of patients had different colonic lesions (13 patients had internal hemorrhoids, 5 patients had colonic diverticula, 4 patients had colonic ulcers with picture suggestive of inflammatory bowel disease (IBD) and 15 patients had no abnormal colonoscopy finding) (Table 1).

Table (1): Lesions detected among the studied cases by colonscopy $(n=200)$

\begin{tabular}{|c|c|c|}
\hline Colonic lesion & Number of cases & \% \\
\hline Polyp & 102 & 51.0 \\
\hline Mass & 61 & 30.5 \\
\hline Other & & \\
\hline Internal haemorrhoids only & 13 & 6.5 \\
\hline Colonic diverticulae only & 5 & 2.5 \\
\hline Colonic ulcers with picture suggestive of IBD & 4 & 2 \\
\hline No abnormal colonoscopic finding & 15 & 7.5 \\
\hline
\end{tabular}

The characteristics of the polyps / masses detected using NBI according to NICE classification and chromo endoscopy according to Kudo's classification showed that: out of 102 patients with polyps; 55 patients had adenomatous polyps, 35 patients had hyperplastic polyps and 12 patients had malignant polyps. While out of 61 patients with masses; 3 patients were adenoma and 58 patients were malignant. Histological characteristics of the polyps were as the following: Adenoma accounted for 55patients distributed as 31cases were tubular adenoma, 9 cases were tubulovillous adenoma, 6 cases were traditional serrated adenoma ,2 cases were TSA with high grade dysplasia , 5 cases were sessile serrated adenoma, 1 case was tubulovillous adenoma with high grade dysplasia, 1 case was villous adenoma. Hyperplastic polyps accounted for 31 cases, inflammatory polyps accounted for 9 cases. Adenocarcinoma accounted for 7 cases. While histological characteristics of the masses were as the following: Adenocarcinoma accounted for 56patients, 4 cases high grade dysplasia (HGD) and one case low grade dysplasia (LGD) (Table 2 \& Figure 1). 
Table(2): Distribution of cases with colonic polyps/massesusing NBI/ chromoendoscopy and Histopathology $(n=163)$

\begin{tabular}{|c|c|c|c|c|c|c|}
\hline Colonic lesions & $\begin{array}{c}\text { NBI/ } \\
\text { chromoendoscopy }\end{array}$ & No. & $\%$ & Histopathology & No. & $\%$ \\
\hline \multirow{11}{*}{ Polyps } & Adenoma & 55 & 33.74 & Adenoma & 55 & 33.74 \\
\hline & Hyperplastic & 35 & 21.47 & Tubular adenoma & 31 & 19.02 \\
\hline & Malignant & 12 & 7.36 & $\begin{array}{c}\text { Tubulovillous } \\
\text { adenoma }\end{array}$ & 9 & 5.52 \\
\hline & & & & $\begin{array}{c}\text { Traditional Serrated } \\
\text { Adenoma(TSA) }\end{array}$ & 6 & 3.68 \\
\hline & & & & $\begin{array}{l}\text { Sessile Serrated } \\
\text { Adenoma }\end{array}$ & 5 & 3.07 \\
\hline & & & & $\begin{array}{l}\text { TSA with high } \\
\text { grade dysplasia }\end{array}$ & 2 & 1.23 \\
\hline & & & & $\begin{array}{l}\text { Tubulovillous } \\
\text { adenoma with high } \\
\text { grade dysplasia }\end{array}$ & 1 & 0.61 \\
\hline & & & & Villous adenoma & 1 & 0.61 \\
\hline & & & & Hyperplastic & 31 & 19.02 \\
\hline & & & & Inflammatory & 9 & 5.52 \\
\hline & & & & Adenocarcinoma & 7 & 4.29 \\
\hline \multirow{3}{*}{ Masses } & Adenoma & 3 & 1.84 & Adenocarcinoma & 56 & 34.36 \\
\hline & Malignant & 58 & 35.58 & $\begin{array}{c}\begin{array}{c}\text { High grade } \\
\text { dysplasia }\end{array} \\
\end{array}$ & 4 & 2.45 \\
\hline & & & & $\begin{array}{l}\text { Low grade } \\
\text { dysplasia }\end{array}$ & 1 & 0.61 \\
\hline
\end{tabular}



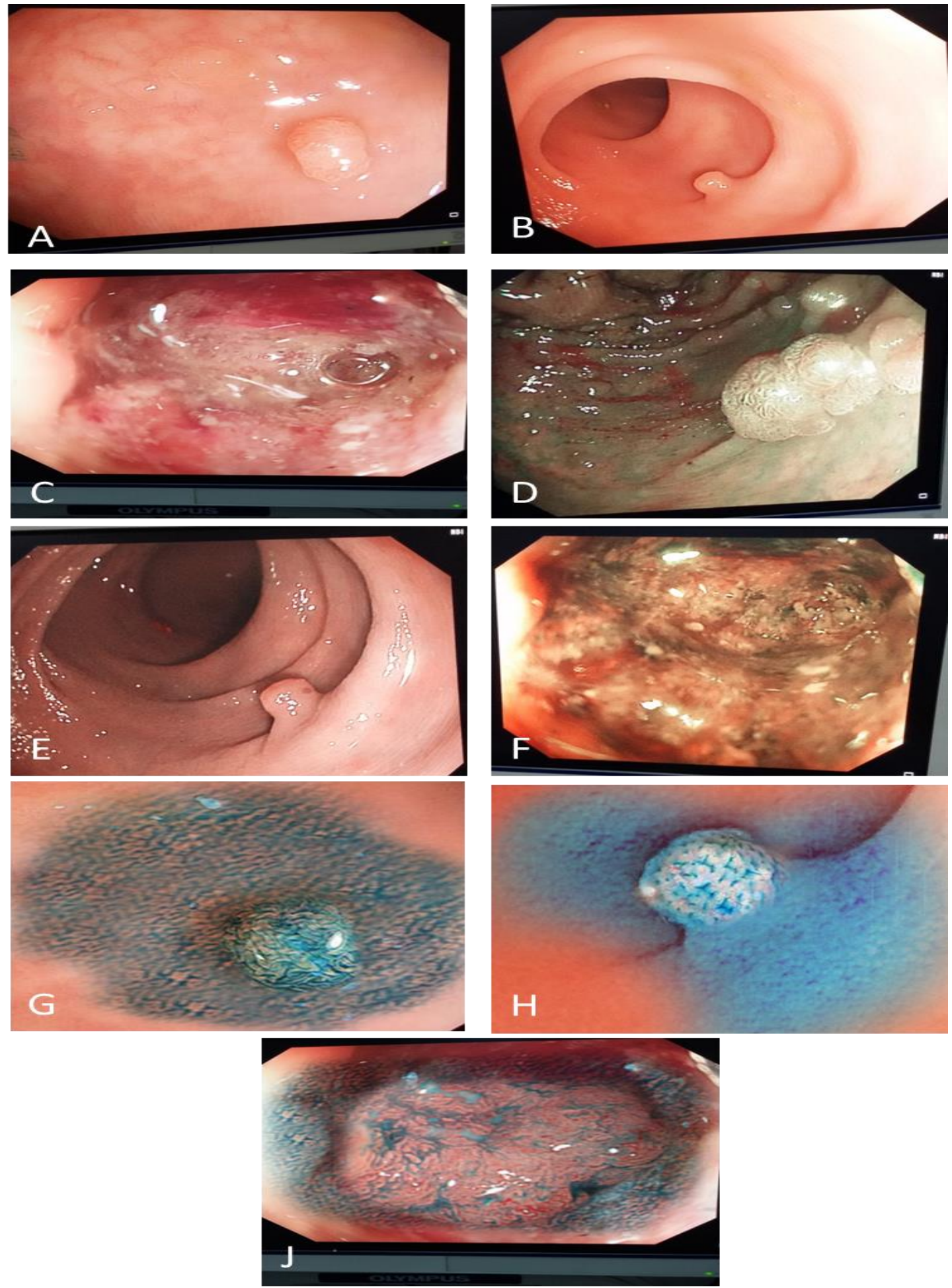

Figure (1): White-light colonoscopy, NBI and chromoendoscopy of colonic polyps and masses. A: sessile polyp at ascending colon by white-light colonoscopy. B: pedunculated polyp at transverse colon by white-light colonoscopy. $C$ : mass at descending colon by white-light colonoscopy. D: adenomatous polyp by NBI. E: hyperplastic polyp by NBI. F: malignant mass by NBI. G: adenomatous polyp by chromoendoscopy. H: hyperplastic polyp by chromoendoscopy. J: malignant mass by chromoendoscopy 
There was a statistically significant relation between histopathological characters of the polyps/masses and their characters by NBI /chromo endoscopy (Table 3).

Table (3): Relation between histopathology finding of colonic polyps/masses and NBI/chromoendoscopy

\begin{tabular}{|c|c|c|c|c|c|c|c|c|c|c|c|c|c|c|c|}
\hline \multirow{3}{*}{\multicolumn{2}{|c|}{$\begin{array}{r}\text { Histopathology } \\
\text { NBI/ }\end{array}$}} & \multicolumn{8}{|c|}{$\begin{array}{l}\text { Polyps } \\
\end{array}$} & \multicolumn{6}{|c|}{ Masses } \\
\hline & & \multicolumn{2}{|c|}{$\begin{array}{c}\text { Adenocar- } \\
\text { cinoma } \\
(\mathrm{n}=7)\end{array}$} & \multicolumn{2}{|c|}{$\begin{array}{c}\text { Hyperplast } \\
\text { ic } \\
(\mathbf{n}=\mathbf{3 1})\end{array}$} & \multicolumn{2}{|c|}{$\begin{array}{c}\text { Inflammat } \\
\text { ory } \\
(\mathrm{n}=9)\end{array}$} & \multicolumn{2}{|c|}{$\begin{array}{c}\text { Adenoma } \\
(\mathbf{n}=\mathbf{5 5})\end{array}$} & \multicolumn{2}{|c|}{$\begin{array}{c}\text { Adenocar } \\
\text { c-inoma } \\
(\mathrm{n}=56)\end{array}$} & \multicolumn{2}{|c|}{$\begin{array}{l}\text { HGD } \\
(n=4)\end{array}$} & \multicolumn{2}{|c|}{$\begin{array}{l}\text { LGD } \\
(\mathbf{n}=\mathbf{1})\end{array}$} \\
\hline & & No & $\%$ & No & $\%$ & No & $\%$ & No & $\%$ & No & $\%$ & No & $\%$ & No & $\%$ \\
\hline \multirow{3}{*}{ Polyp } & Adenoma & 0 & 0 & 2 & 6.5 & 3 & $\begin{array}{c}33 . \\
3\end{array}$ & 50 & $\begin{array}{c}90 . \\
9\end{array}$ & 0 & 0 & 0 & 0 & 0 & 0 \\
\hline & Hyperplastic & 0 & 0 & 29 & 93.5 & 6 & 6.7 & 0 & 0 & 0 & 0 & 0 & 0 & 0 & 0 \\
\hline & Malignant & 7 & 100 & 0 & 0 & 0 & 0 & 5 & 9.1 & 0 & 0 & 0 & 0 & 0 & 0 \\
\hline \multirow{2}{*}{ Mass } & Adenoma & 0 & 0 & 0 & 0 & 0 & 0 & 0 & 0 & 0 & 0 & 2 & 50 & 1 & 100 \\
\hline & Adenocarcinoma & 0 & 0 & 0 & 0 & 0 & 0 & 0 & 0 & 56 & 100 & 2 & 50 & 0 & 0 \\
\hline${ }^{\mathrm{MC}} \mathbf{p}$ & \multicolumn{15}{|c|}{$<0.001 *$} \\
\hline
\end{tabular}

Chi square test

NBI /chromo endoscopy can detect adenocarcinoma with $100 \%$ sensitivity and $94.7 \%$ specificity. Sensitivity and specificity for hyperplastic polyp was $93.5 \%$ and $91.5 \%$ respectively . While for adenoma was $90.9 \%$ and $89.4 \%$ respectively. Sensitivity and specificity for malignant mass was $100 \%$ and $60 \%$ respectively (Table 4).

Table (4): Agreement (sensitivity, specificity and accuracy) for NBI/ chromoendoscopy to detect colonic polyps/masses $(n=163)$

\begin{tabular}{|c|c|c|c|c|c|c|c|c|c|}
\hline \multirow{2}{*}{$\begin{array}{l}\text { NBI/ } \\
\text { Chromoendoscopy }\end{array}$} & \multicolumn{2}{|c|}{-ve } & \multicolumn{2}{|c|}{$+v e$} & \multirow{2}{*}{ 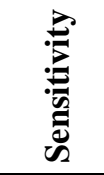 } & \multirow{2}{*}{ 莺 } & \multirow{2}{*}{$\vec{a}$} & \multirow{2}{*}{$\vec{z}$} & \multirow{2}{*}{ 递 } \\
\hline & No. & $\%$ & No. & $\%$ & & & & & \\
\hline \multicolumn{10}{|l|}{ Adenocarcinoma polyps } \\
\hline -ve & 90 & 94.7 & 0 & 0 & \multirow{2}{*}{100.0} & \multirow{2}{*}{94.7} & \multirow{2}{*}{58.3} & \multirow{2}{*}{100.0} & \multirow{2}{*}{95.1} \\
\hline$+\mathrm{ve}$ & 5 & 5.3 & 7 & 100 & & & & & \\
\hline$\square^{2}(\mathbf{p})$ & \multicolumn{4}{|c|}{$56.368 *(<0.001 *)$} & & & & & \\
\hline \multicolumn{5}{|l|}{ Hyperplastic polyps } & \multirow{3}{*}{93.5} & \multirow{3}{*}{91.5} & \multirow{3}{*}{82.9} & \multirow{3}{*}{97.0} & \multirow{3}{*}{92.2} \\
\hline -ve & 65 & 91.5 & 2 & 6.5 & & & & & \\
\hline$+\mathrm{ve}$ & 6 & 8.5 & 29 & 93.5 & & & & & \\
\hline$\square^{2}(\mathbf{p})$ & \multicolumn{4}{|c|}{$69.329 *(<0.001 *)$} & \multirow{4}{*}{90.9} & & & & \\
\hline \multicolumn{5}{|l|}{ Adenomatous polyps } & & \multirow{3}{*}{89.4} & \multirow{3}{*}{90.9} & \multirow{3}{*}{89.4} & \multirow{3}{*}{90.2} \\
\hline -ve & 42 & 89.4 & 5 & 9.1 & & & & & \\
\hline$+\mathrm{ve}$ & 5 & 10.6 & 50 & 90.9 & & & & & \\
\hline$\square^{2}(\mathbf{p})$ & \multicolumn{4}{|c|}{$65.723 *(<0.001 *)$} & & & & & \\
\hline Adenocarcinoma masses & & & & & \multirow{3}{*}{100} & \multirow{3}{*}{60} & \multirow{3}{*}{96.6} & \multirow{3}{*}{100} & \multirow{3}{*}{96.7} \\
\hline -ve & 3 & 60 & 0 & 0 & & & & & \\
\hline +ve & 2 & 40 & 56 & 100 & & & & & \\
\hline$\square^{2}(\mathbf{p})$ & \multicolumn{4}{|c|}{$35.338 *(<0.001 *)$} & & & & & \\
\hline
\end{tabular}

$\chi^{2}, \mathrm{p}: \chi^{2}$ and $\mathrm{p}$ values for Chi square test for comparing between the two groups. 


\section{DISCUSSION}

This study was carried out on 200 patients admitted to endoscopy unit for different causes. The aim of this work was to assess the role of NBI colonoscopy for detection and differentiation of colorectal polyps and masses versus chromo endoscopy and conventional colonoscopy. The most common complaint was bleeding per rectum in $36 \%$ of our patients, bowel changes was the presenting symptom in $19 \%$, abdominal pain in $21 \%$, anemia in $25 \%$, constipation in $7.5 \%, 3.5 \%$ had history of polypectomy and $3 \%$ with family history of CRC.

Vişovan et al. (2017) studied the role of narrow band imaging in colorectal polyps detection showed that the most common complaint was intestinal transit disorders $22.5 \%$, and the second common was rectal bleeding $19.9 \%$.

Because of the association of colonic polyps with CRC, detection and differentiation of the polyps are very important .Many methods can be used for detection of colorectal polyps as fecal occult blood testing, fecal DNA testing, CT enterocolonography and colonoscopy (Garber et al., 2015). Cellier et al. (2019) verified the feasibility of examining the "pit patterns" of the colonic polyp to differentiate between these two polyps via magnified endoscopy and indigo carmine dye contrast.

The NBI system utilizes light in short, limited wavelengths that allow visualization of the hemoglobin absorption band, such as that indicative of blood vessels, with adequate contrast via a single touch of the control switch (Utsumi et al., 2015).
In this study, the polyps were distributed according to its histopathological characteristics as the following $53.92 \%$ of patients had adenomatous polyp, $30.39 \%$ had hyperplastic polyps and $6.86 \%$ were malignant. And according to NBI using NICE classification or chromo endoscopy using Kudo classification into $53.92 \%$ had polyps adenomatous in nature, $34.31 \%$ had hyperplastic polyps and $11.76 \%$ were malignant. Thus statically significant relation between the histopatological characteristics and NBI/ chromo endoscopy features was proved $(\mathrm{P}<$ $0.001)$. The sensitivity for adenoma was $90.9 \%$, specificity $89.4 \%$ and accuracy $90.2 \%$.The sensitivity for hyperplastic polyps $93.5 \%$, specificity $91.5 \%$ and accuracy $92.2 \%$. The sensitivity for adenocarcinoma was $100 \%$, specificity $94.7 \%$ and accuracy $95.1 \%$.

Vișovan et al. (2017) studied the role of narrow band imaging in colorectal polyps detection. In NBI group, histopathologicaly, $66.15 \%$ adenomas, $32.62 \%$ hyperplastic polyps, and $1.23 \%$ carcinomas .The sensitivity and specificity of NBI technique combined with the NICE classification in predicting the results of histological analysis were $90.9 \%$ and $95.2 \%$, respectively. The accuracy of NBI without magnification combined with the NICE classification in polyp characterization was $91.1 \%$.

In contrast to this study, Azevedo et al. (2018) studied resect and discard /diagnose and disregard strategy for colonic polyps in community hospital using NBI and NICE classification without previous experience on 147 patients, the polyps were distributed 
according histology to hyperplastic $37.5 \%$; sessile serrated polyps $10.5 \%$; adenoma $49.5 \%$ and carcinoma $0 \%$ and according to NICE classification hyperplastic $44 \%$; sessile serrated polyps $4 \%$; adenoma $50.5 \%$; carcinoma $1.5 \%$ accuracy, sensitivity, specificity, positive predictive value and negative predictive value of $78.4 \%, 77.4 \%, 80 \%, 85.3 \%$ and $77.1 \%$, respectively.

In this study, the masses were distributed according to its histopathological characteristics as the following, $91.8 \%$ of patients had adenocarcinoma, $6.6 \%$ with high grade dysplasia (HGD) and $1.6 \%$ with low grade dysplasia (LGD). And according to NBI via NICE classification into $4.9 \%$ had adenoma, 95.1\% had malignant mass. And according to chromo endoscopy via Kudo's classification into $4.92 \%$ had adenoma, 95.08\% had malignant mass. Thus, a statically significant relation between the histopatological characteristics and NBI features using NICE classification or chromo endoscopy using Kudo classification was proved ( $\mathrm{P}<$ $0.0001)$. The sensitivity was $100 \%$, specificity $60 \%$ and accuracy $96.7 \%$.

In agreement with this results, Wada et al. (2012) studied diagnostic accuracy of pit pattern and vascular pattern in colorectal lesions on 584 cases revealed sensitivity $100 \%$, specificity $71 \%$, and accuracy 96.1\%. Fukuzawa et al. (2012) studied Effectiveness of narrow-band imaging magnification for invasion depth in early colorectal cancer, sensitivity was $81.4 \%$ and accuracy was $92.9 \%$.

In contrast to this study, Sumimoto et al. (2017) studied clinical impact and characterization of NBI magnifying endoscopic classification of colorectal tumors by using Japanese Narrow band Expert Team (JNET) classification, sensitivity was $55.4 \%$, specificity $99.8 \%$ but accuracy was $96.6 \%$.

The reasons for different levels of accuracy can be multiple, for example, related to the level of expertise of physicians who performed classifications, colonoscopies equipment used, the polyp sizes and bowel preparation (Patrun et al., 2018).

\section{CONCLUSION}

In this study, we proved the role of NBI in detection of either colorectal polyp or mass and prediction of its histology using NICE classification. Also it is simple, accurate, applicable, and rapid in comparison to chromo endoscopy which needs stains and time consuming. Thus NBI using NICE classification can be used to avoid discarding significant lesions and removing no significant lesions that lead to less complications and more cost saving.

\section{REFERENCES}

1. Azevedo R, Pereira F, Linhares M, Ribeiro H, Pinto J and Caldeira A (2018): Resect and discard/diagnose and disregard strategy for colonic polyps in a community hospital: are we able to implement it? Endosc; 50(4): 71.

2. Carlo S, Danielle R, Alessandro M, Mauro B, Claudio D and Chiara G (2014): Narrow band imaging vs. high definition colonoscopy for detection of colorectal adenomas in patients with positive faecal occult blood test: A randomized trial. Dig Liver Dis; 46: 10.

3. Cellier C, Perrod G, Colas C,Dhooge M, Saurin J and Lecomte T (2019): Back-toback comparison of colonoscopy with virtual chromo endoscopy using a third-generation narrow- band imaging system to chromo 
endoscopy with indigo carmine in patients with lynch syndrome. Am J Gastroenterol;114(10):1665-1670.

4. Fukuzawa M, Saito Y, Matsuda T, Uraoka T, Itoi $T$ and Moriyasu $F$ (2012): Effectiveness of narrow-band imaging magnification for invasion depth in early colorectal cancer. World J Gastroenterol; 16: 1727-1734.

5. Garber JJ and Chung DC (2015): Polyps of the Colon and Rectum. Yamada's Textbook of Gastroenterology: Pbl.John Wiley \& Sons, Ltd; p. 1537-1553.

6. Kheir AO, Soetikno $R$ and Kaltenbach $T$ (2016): Chromo endoscopy. In: Konda VJA, Waxman I. editors. Endoscopic Imaging Techniques and Tools. Pbl. Switzerland: Springer International Publishing: 29-49.

7. Patrun J, Okreša L, Iveković $H$ and Rustemović N (2018): Diagnostic accuracy of nice classification system for optical recognition of predictive morphology of colorectal polyps. Gastroenterol Res Pract; $14: 7531368$.
8. Sumimoto K, Tanaka S, Shigita K, Hirano D, Tamaru $Y$ and Ninomiya $Y$ (2017): Clinical impact and characteristics of the narrow-band imaging magnifying endoscopic classification of colorectal tumors proposed by the Japan NBI Expert Team. Gastrointest Endoscopy; 85(4):816-821.

9. Utsumi T, Iwatate M, Sano W, Sunakawa H, Hattori S and Hasuike N (2015): Polyp detection, characterization, and management using narrow-band imaging with/without magnification. ClinEndosc; 48(6):491.

10. Vişovan II, Tanțău M, Pascu O, Ciobanu L and TanțăuA (2017): The role of narrow band imaging in colorectal polyp detection. Bosn J Basic Med Sci; 17(2):152.

11. Wada Y, Kashida H, Kudo SE, Misawa M, Ikehara $N$ and Hamatani $S$ (2012): Diagnostic accuracy of pit pattern and vascular pattern analyses in colorectal lesions. Dig Endosc; 22:192-199. 


\section{تقنية الحزمه الضيقه في تصوير منظار القولون مقارنه

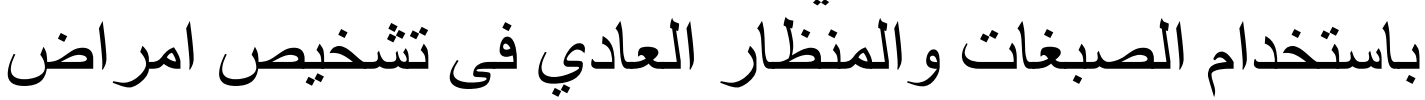 القولون المختلفه}

جلال أبوفراج1، محمد بسطاوي1، علي ابراهيم1، ناصر الفقي، أحمد حشيش1 1قسم أمراض الكبد والجهاز الهضمي والأمراض المعديه، كليه طب الازهر

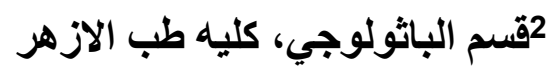

E-mail: drgalal2009@yahoo.com

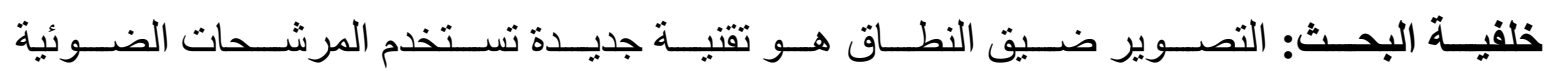

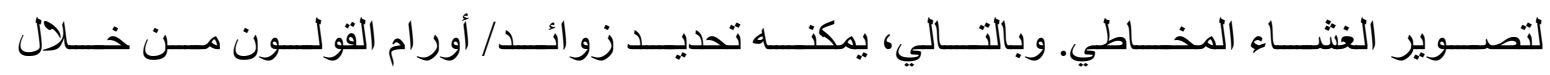

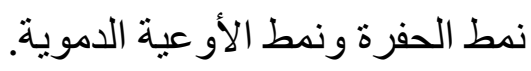

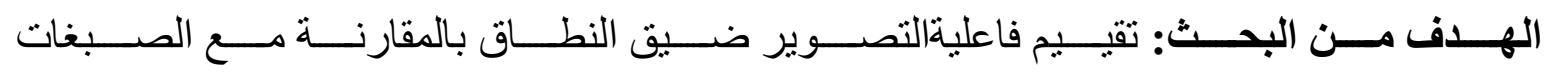
و المنظار العادي للكثف عن أورام القولون والمستقيم.

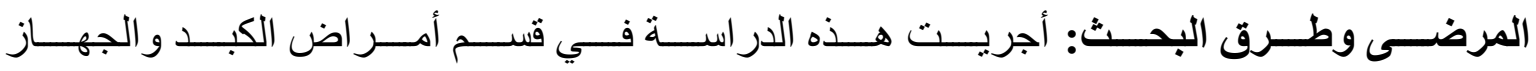

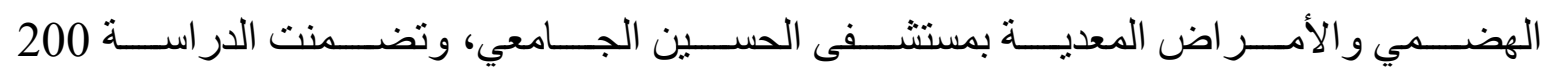

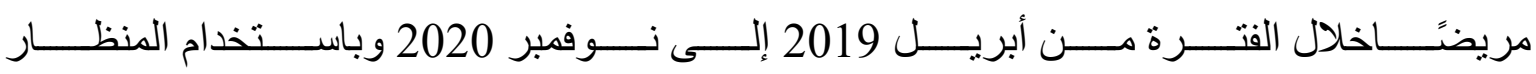

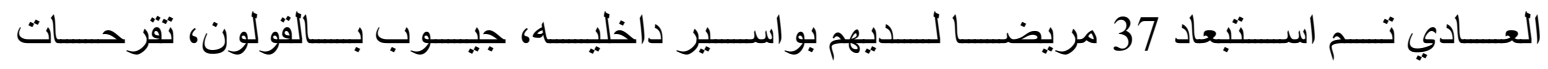

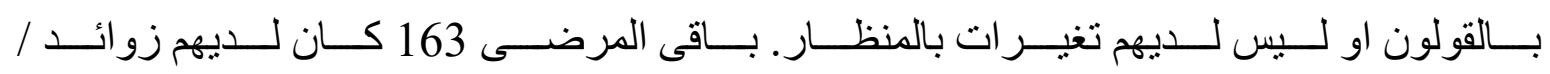

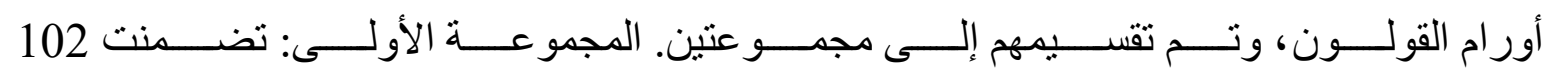

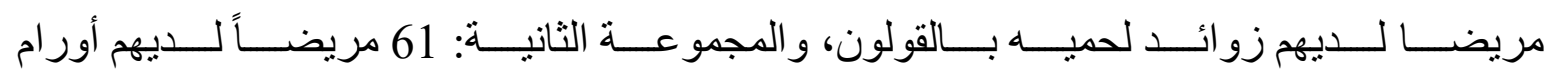

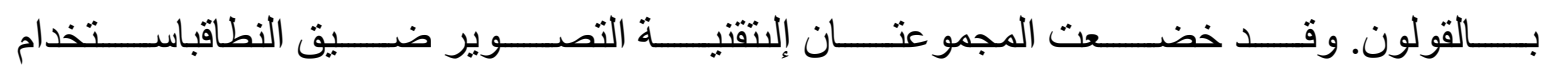

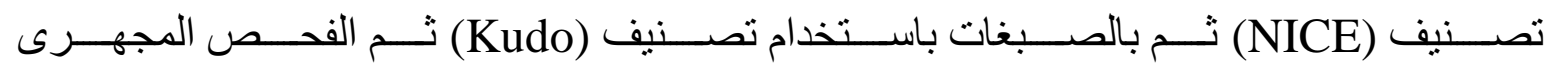
للعينات.

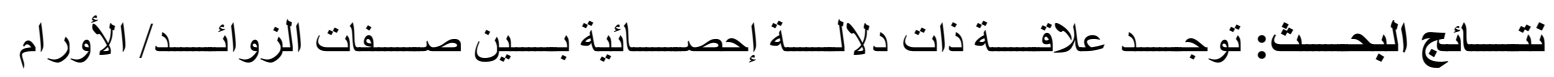

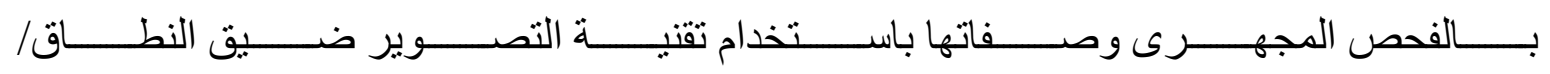

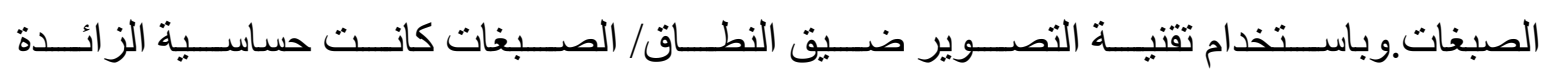




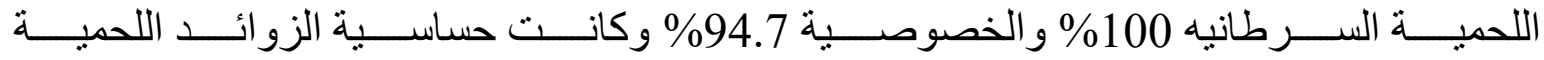

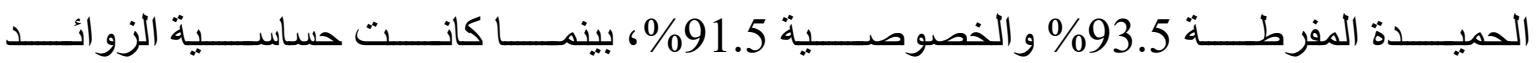

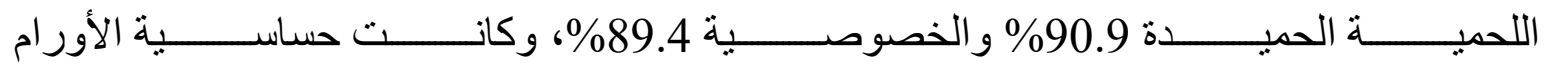
السرطانيه 100\% و الخصوصية \%0\%.

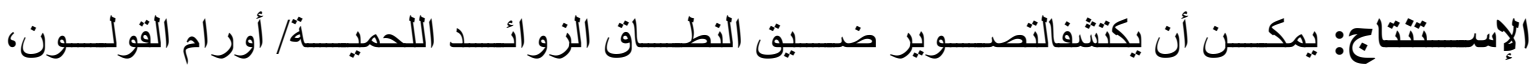

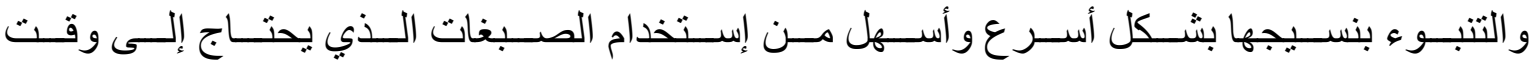

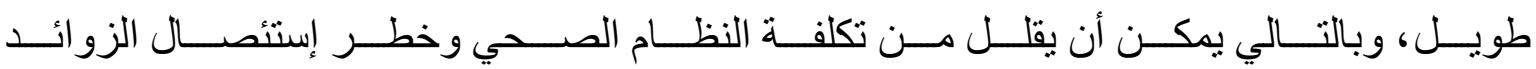
اللحمية.

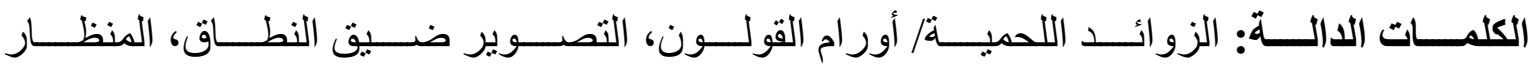
باستخدام الصبغات. 